\title{
Atmospheric Sulfuric Acid-Dimethylamine Nucleation Enhanced by Trifluoroacetic Acid
}

\section{Lu, Yiqun}

2020-01-28

Lu , Y, Liu , L, Ning , A, Yang , G, Liu , Y, Kurten , T, Vehkamäki , H , Zhang , X \& Wang , L 2020 , ' Atmospheric Sulfuric Acid-Dimethylamine Nucleation Enhanced by Trifluoroacetic Acid ', Geophysical Research Letters , vol. 47 , no. 2 , ARTN e2019GL085627 . https://doi.org/10.1029/2019GL0856

http://hdl.handle.net/10138/322345

https://doi.org/10.1029/2019GL085627

publishedVersion

Downloaded from Helda, University of Helsinki institutional repository.

This is an electronic reprint of the original article.

This reprint may differ from the original in pagination and typographic detail.

Please cite the original version. 


\section{Geophysical Research Letters}

\author{
RESEARCH LETTER \\ 10.1029/2019GL085627 \\ Key Points: \\ - Theoretical simulations indicate \\ complex atmospheric new particle \\ formation mechanisms involving \\ sulfuric acid, dimethylamine, and \\ trifluoroacetic acid \\ - Good agreement of key cluster \\ concentrations between simulations \\ and ambient measurements during \\ new particle formation events is \\ obtained \\ - Trifluoroacetic acid can participate \\ in the growth of sulfuric \\ acid-dimethylamine clusters and \\ enhance the nucleation rates
}

Supporting Information:

- Supporting Information S1

Correspondence to: $\mathrm{X}$. Zhang and L. Wang, lin_wang@fudan.edu.cn; zhangxiuhui@bit.edu.cn

Citation:

Lu, Y., Liu, L., Ning, A., Yang, G., Liu, Y., Kurtén, T., et al. (2020). Atmospheric sulfuric

acid-dimethylamine nucleation enhanced by trifluoroacetic acid. Geophysical Research Letters, 47, e2019GL085627. https://doi.org/ 10.1029/2019GL085627

Received 2 OCT 2019 Accepted 4 JAN 2020

Accepted article online 7 JAN 2020

Yiqun Lu and Ling Liu contributed equally to this work.

(C)2020. American Geophysical Union. All Rights Reserved.

\section{Atmospheric Sulfuric Acid-Dimethylamine Nucleation Enhanced by Trifluoroacetic Acid}

\author{
Yiqun Lu ${ }^{1}$, Ling Liu ${ }^{2}$, An Ning ${ }^{2}$, Gan Yang ${ }^{1}$, Yiliang Liu ${ }^{1}$, Theo Kurtén ${ }^{3}$, Hanna Vehkamäki ${ }^{4}$, \\ Xiuhui Zhang ${ }^{2}$, and Lin Wang ${ }^{1,5,6}$ \\ ${ }^{1}$ Shanghai Key Laboratory of Atmospheric Particle Pollution and Prevention (LAP ${ }^{3}$ ), Department of Environmental \\ Science \& Engineering, Jiangwan Campus, Fudan University, Shanghai, China, ${ }^{2}$ Key Laboratory of Cluster Science, \\ Ministry of Education of China, School of Chemistry and Chemical Engineering, Beijing Institute of Technology, Beijing, \\ China, ${ }^{3}$ Department of Chemistry, University of Helsinki, Helsinki, Finland, ${ }^{4}$ Institute for Atmospheric and Earth System \\ Research/Physics, Faculty of Science, University of Helsinki, Helsinki, Finland, ${ }^{5}$ Collaborative Innovation Center of \\ Climate Change, Nanjing, China, ${ }^{6}$ Shanghai Institute of Pollution Control and Ecological Security, Shanghai, China
}

Abstract Sulfuric acid (SA)-dimethylamine (DMA)- $\mathrm{H}_{2} \mathrm{O}$ cluster formation has been proven to be responsible for a significant part of new particle formation (NPF) in a Chinese megacity. However, the possible involvement of common atmospheric acids in the subsequent growth of SA-DMA clusters remains elusive. We simulated formation and growth of clusters using atmospheric relevant concentrations of SA, DMA, and trifluoroacetic acid (TFA), a commonly observed atmospheric perfluorocarboxylic acid, using Density Functional Theory combined with Atmospheric Cluster Dynamics Code. The presence of TFA leads to complex cluster formation routes and an enhancement of NPF rates by up to 2.3 ([TFA] $=5.0 \times 10^{6}$ molecules $\mathrm{cm}^{-3},[\mathrm{SA}]=1.0 \times 10^{6}$ molecules $\mathrm{cm}^{-3}$, and $[\mathrm{DMA}]=1.5 \times 10^{9}$ molecules $\mathrm{cm}^{-3}$ ). The agreement of $(\mathrm{SA})_{1} \cdot(\mathrm{DMA})_{1-2} \cdot(\mathrm{TFA})_{1}$ concentrations between simulations and ambient measurements during NPF events validates model predictions and implies that perfluorocarboxylic acids could potentially boost atmospheric SA-DMA NPF rates.

Plain Language Summary Atmospheric nucleation is the earliest step to form new aerosol particles, which includes a complex transformation from gaseous molecules to small clusters, then to critical clusters, and finally to freshly nucleated nanoparticles. Sulfuric acid and dimethylamine have been proved to explain atmospheric nucleation events in urban China. However, whether other atmospheric acidic species could participate in this nucleation process remains elusive. Herein, we report a sulfuric aciddimethylamine based nucleation mechanism with the participation of trifluoroacetic acid, a commonly observed strong acid in the atmosphere, using theoretical calculation methods. The model predictions are then validated by ambient measurements in urban Shanghai. Our results suggest that perfluorocarboxylic acids could potentially boost the formation of nanoparticles.

\section{Introduction}

The formation of atmospheric aerosol particles is of great interest because of the atmospheric particles' impact on climate and health. New particle formation (NPF) events are considered to be a dominant source of atmospheric aerosol particles in terms of the number concentration at the global scale (Dunne et al., 2016). Depending on known and yet-to-be-elucidated atmospheric parameters, ambient NPF events occur via different mechanisms at different locations, for example, sulfuric acid (SA)-oxygenated organic compounds- $\mathrm{H}_{2} \mathrm{O}$ nucleation in boreal forest, Finland (Kulmala et al., 2013; Schobesberger et al., 2013), SA-ammonia- $\mathrm{H}_{2} \mathrm{O}$ nucleation or pure biogenic nucleation in Jungfraujoch, Switzerland (Bianchi et al., 2016), iodic acid nucleation in Mace Head, Ireland (Sipilä et al., 2016), ion-induced SA-ammonia nucleation in coastal Antarctica (Jokinen et al., 2018), and SA-dimethylamine (DMA) nucleation in urban Shanghai, China (Yao et al., 2018). Determining the mechanism of ambient NPF events is largely based on the identification of key clusters, whose concentration profiles, together with NPF rates, match those in laboratory experiments with preset and controlled precursor concentrations. Due to the complex nature of the atmosphere and the potential limitations of the popularly used detection instruments, such as atmospheric pressure interface time-of-flight mass (APi-TOF) spectrometer and chemical ionization-atmospheric pressure interface time-of-flight (CI-APi-TOF) mass spectrometer, many chemical species and clusters potentially 
Table 1

The Gibbs Free Energies for Cluster Formation at a Reference Pressure of $1 \mathrm{~atm}\left(\Delta G_{\text {ref, }} \mathrm{kcal} \mathrm{mol}^{-1}\right)$ and the Overall Evaporation Coefficients $\left(\Sigma \gamma, \mathrm{s}^{-1}\right)$ of $(S A)_{x} \cdot(D M A)_{y} \cdot(T F A)_{z}(1 \leq y \leq(x+z) \leq 3,1 \leq x, 1 \leq z)$ Clusters at $280 \mathrm{~K}$ at $R I$-CC2/aug-cc- $p V(T+d) Z / / M 06-2 X / 6-311++G(3 d f, 3 p d)$ Level of Theory

\begin{tabular}{lcc}
\hline Clusters & $\Delta G_{\text {ref }}\left(\mathrm{kcal} \mathrm{mol}^{-1}\right)$ & $\Sigma \gamma\left(\mathrm{s}^{-1}\right)$ \\
\hline$(\mathrm{SA})_{1} \cdot(\mathrm{DMA})_{1} \cdot(\mathrm{TFA})_{1}$ & -27.21 & 3.77 \\
$(\mathrm{SA})_{1} \cdot(\mathrm{DMA})_{2} \cdot(\mathrm{TFA})_{1}$ & -44.92 & $1.73 \times 10^{-4}$ \\
$(\mathrm{SA})_{2} \cdot(\mathrm{DMA})_{1} \cdot(\mathrm{TFA})_{1}$ & -42.13 & $2.10 \times 10^{5}$ \\
$(\mathrm{SA})_{1} \cdot(\mathrm{DMA})_{1} \cdot(\mathrm{TFA})_{2}$ & -36.32 & $6.44 \times 10^{2}$ \\
$(\mathrm{SA})_{2} \cdot(\mathrm{DMA})_{2} \cdot(\mathrm{TFA})_{1}$ & -61.91 & $1.16 \times 10^{6}$ \\
$(\mathrm{SA})_{1} \cdot(\mathrm{DMA})_{2} \cdot(\mathrm{TFA})_{2}$ & -52.41 & $1.31 \times 10^{4}$ \\
$(\mathrm{SA})_{2} \cdot(\mathrm{DMA})_{3} \cdot(\mathrm{TFA})_{1}$ & -79.52 & $2.31 \times 10^{-4}$ \\
$(\mathrm{SA})_{1} \cdot(\mathrm{DMA})_{3} \cdot(\mathrm{TFA})_{2}$ & -68.39 & $4.23 \times 10^{-3}$ \\
\hline
\end{tabular}

important to NPF have not been determined in previous studies. As a result, the contribution of other atmospheric trace gases to NPF events, in addition to the species that have already been proved to play a key role, remains to be clarified. For example, clusters consisting of SA, DMA, and atmospheric acids have not been detected in field measurements, though a couple of theoretical studies suggest that acidic species (e.g., methane sulfonic acid, Bork et al., 2014; Dawson et al., 2012; sulfamic acid, Li, Zhong, et al., 2018; lactic acid, Li et al., 2017; and succinic acid, Lin et al., 2019) can enhance SA-DMA nucleation due to their acidity via the formation of stabilized clusters. The acidity of perfluorocarboxylic acids is potentially relatively strong due to the electron-withdrawing inductive effect of the fluorine atoms. However, whether or not common atmospheric perfluorocarboxylic acids are involved in the growth of SADMA clusters is unknown.

In this study, we simulated SA-DMA-TFA nucleation under atmospherically relevant conditions. The formation routes of clusters were computed using Density Functional Theory combined with the Atmospheric Cluster Dynamics Code (ACDC). We also measured the corresponding molecules and clusters in urban Shanghai with a nitrate-based CI-APi-TOF mass spectrometer, as described in Supporting Information S1. TFA, the simplest atmospheric perfluorocarboxylic acid formed mainly through degradations of the Freon alternatives such as hydrofluorocarbons, hydrochlorofluorocarbons, and hydrofluoro-olefins from anthropogenic sources (Tromp et al., 1995; Wang et al., 2018; Wu et al., 2014), was chosen because of its atmospheric abundance, acidity, and potency to form hydrogen bonds (Asfin, 2019; Nahringbauer et al., 1979).

\section{Materials and Methods}

The studied clusters include $(\mathrm{SA})_{x} \cdot(\mathrm{DMA})_{y} \cdot(\mathrm{TFA})_{z}$, where $0 \leq y \leq(x+z) \leq 3$, that is, only clusters with the number of acidic molecules no less than that of basic molecules are considered, because they are relatively stable and could potentially participate in the main cluster formation routes (Olenius et al., 2013). Among these clusters, the structures of $(\mathrm{SA})_{x} \cdot(\mathrm{DMA})_{y}(0 \leq y \leq x \leq 3)$ clusters are taken from a previous study ( $\mathrm{Li}$, Zhang, et al., 2018; Li et al., 2020). The smallest clusters outside of the ACDC simulation are $(\mathrm{SA})_{4} \cdot(\mathrm{DMA})_{3}$ and $(\mathrm{SA})_{3} \cdot(\mathrm{DMA})_{4} \cdot(\mathrm{TFA})_{1}$, which are assumed to be very stable (McGrath et al., 2012) (section S1). The structure optimization and thermodynamic parameters of molecules and clusters were calculated at M06-2X/6-311++G(3df,3pd) level of theory. Previous studies have shown that the geometries of the optimized structures at M06-2X/6-311++G(3df,3pd) level of theory are in relatively good agreement with experimental results (Elm et al., 2012; Zhao \& Truhlar, 2008). Thus, M06-2X/6-311++G(3df,3pd) is considered to be an accurate and adequate computational level to obtain the molecular cluster geometries and vibrational frequencies. Further single point energy calculations at RI-CC2/aug-cc-pV(T $+d) Z$ level have been performed using TURBOMOLE program (Dunning et al., 2001; Hättig \& Weigend, 2000). The particle formation rates predicted using the ACDC (McGrath et al., 2012) kinetic model combined with RI-CC2/augcc-pV(T + d)Z//B3LYP/CBSB7 (Almeida et al., 2013) are in good agreement with the experimental formation rates measured in the CLOUD chamber (Kürten et al., 2018) (Figure S1). In addition, the simulated SA dimer concentrations from RI-CC2/aug-cc-pV(T $+\mathrm{d}) \mathrm{Z} / / \mathrm{M} 06-2 \mathrm{X} / 6-311++\mathrm{G}(3 \mathrm{df}, 3 \mathrm{pd})$ in the present work are in better agreement with the measured ones in Shanghai (Yao et al., 2018), than those from DLPNO-CCSD(T)/aug-cc-pVTZ//wB97X-D/6-31++G(d,p) (Xie et al., 2017) (Figure S2). These agreements may be due to a random cancellation of errors, which is not within the scope of this study but should be revealed in forthcoming studies.

The formation mechanism of the clusters and the cluster formation rate, $J$, in the SA-DMA-TFA system have been simulated using ACDC, which generates the birth-death equations for a certain set of clusters and solves the time development of each cluster concentration explicitly by numerical integration using the ode15s solver of MATLAB (Shampine \& Reichelt, 1997). In the SA-DMA-TFA system, the SA concentration was set to be $0.04-1.6$ parts per trillion by volume (pptv, $1.0 \times 10^{6}-4.0 \times 10^{7}$ molecules $\mathrm{cm}^{-3}$ ), and the TFA concentration was fixed at $0.2 \mathrm{pptv}\left(5.0 \times 10^{6}\right.$ molecules $\left.\mathrm{cm}^{-3}\right)$. The latter value was based on both previously 
[TFA] $=5.0 \times 10^{6}$ molecules $\mathrm{cm}^{3}$, [SA] $=5.0 \times 10^{6}$ molecules $\mathrm{cm}^{3}$, [DMA] $=1.5 \times 10^{9}$ molecules $\mathrm{cm}^{-3}, \mathrm{CS}=0.02 \mathrm{~s}^{-1}$

a)

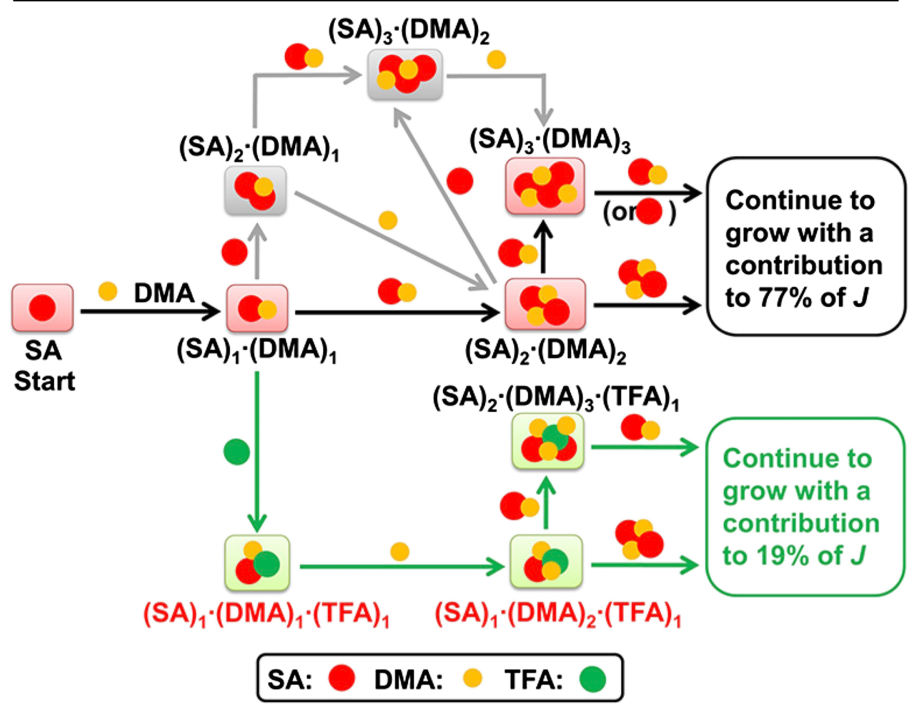

b)

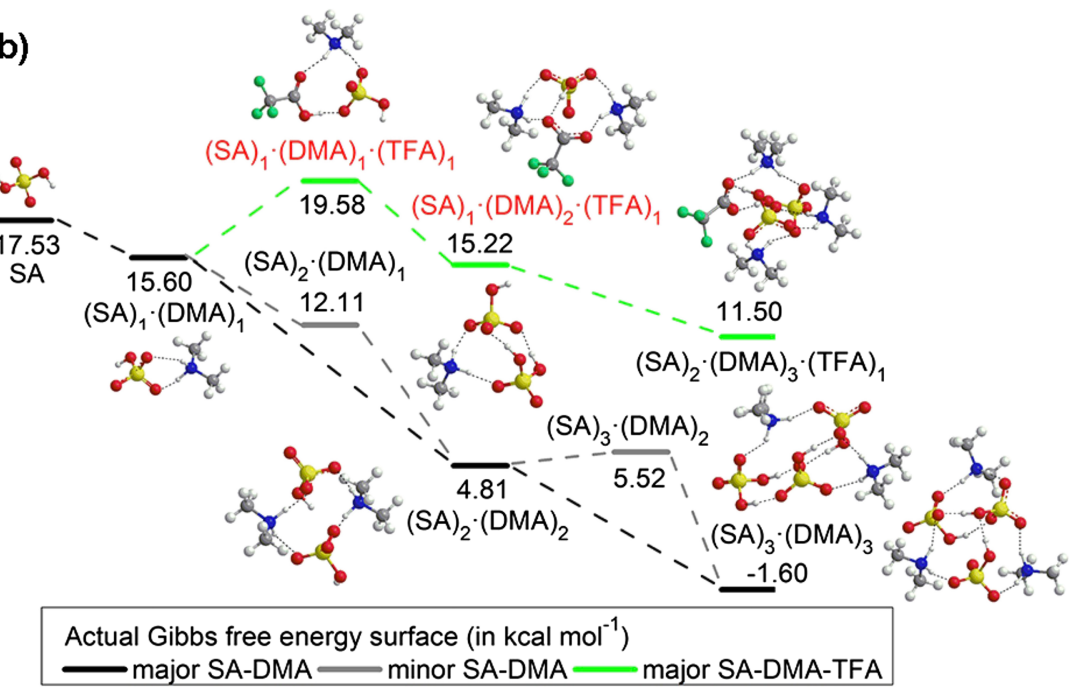

Figure 1. (a) Cluster formation routes of the SA-DMA-TFA system at $280 \mathrm{~K}$ simulated by ACDC. Black and gray arrows denote the major and minor SA/DMA nucleation routes, respectively, and green ones denote the SA/DMA/TFA nucleation route. (b) Actual Gibbs free energies for the formation of clusters at $280 \mathrm{~K}$. The gray, white, red, blue, yellow, and green balls represent $\mathrm{C}, \mathrm{H}, \mathrm{O}, \mathrm{N}, \mathrm{S}$, and F atoms, respectively. Hydrogen bonds are shown in dashed lines. The clusters in the red font were detected in the field study.

reported gas-phase TFA concentrations of 800-1,860 $\mathrm{pg} \mathrm{m}^{-3}$ (about $4.0 \times 10^{6}-1.0 \times 10^{7}$ molecules $\mathrm{cm}^{-3}$ ) in Beijing (Wu et al., 2014; Zhang et al., 2018), which is a comparable megacity to Shanghai, and on our own atmospheric measurements in Shanghai in the present study, which show gas-phase TFA concentrations in the range of $1.3 \times 10^{6}-10.1 \times 10^{6}$ molecules $\mathrm{cm}^{-3}$ (10-90\% percentiles, 10-min time resolution) (Figure S3) after taking into account the interference from the Teflon materials within the instrument setup. The DMA concentration was fixed at $60 \mathrm{pptv}\left(1.5 \times 10^{9}\right.$ molecules $\left.\mathrm{cm}^{-3}\right)$, which is roughly the upper bound concentration in a previous measurement for C-2 amines in Shanghai (Mao et al., 2018; Yao et al., 2016). Details about the setting of temperature and concentrations of species in the simulation are shown in section S1. The condensation sink (CS) was set to be $0.01,0.02$, and $0.03 \mathrm{~s}^{-1}$ corresponding to previous observations in Shanghai (Yao et al., 2018). 


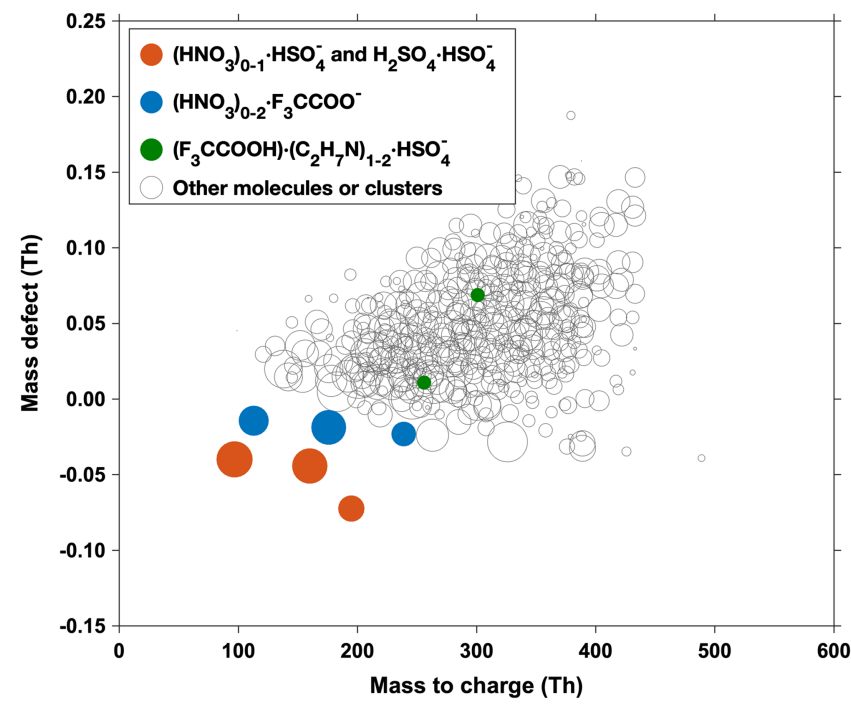

Figure 2. Mass defect plot of charged molecules and clusters measured in urban Shanghai by a nitrate-based chemical ionization-atmospheric pressure interface time-of-flight mass spectrometer (09:00 to 16:00 local time, 9 January 2018). The symbol size is proportional to the logarithm of the arbitrary signal.
Atmospheric measurements were carried out on the rooftop of a teaching building of Fudan University between 19 December 2017 and 10 January 2018. The detailed description of the site can be found in Xiao et al. (2015). CI-APi-TOF equipped with a nitrate chemical ionization source (Aerodyne Research, Inc.) was used to quantitatively measure atmospheric concentrations of relevant molecules and clusters (section S2).

\section{Results and Discussion}

\subsection{Stability of Clusters}

The most stable structures of SA-DMA-TFA clusters ((SA) $\cdot$.(DMA) $\left.y \cdot(\mathrm{TFA})_{z}, 0 \leq y \leq(x+z) \leq 3\right)$ were calculated at the M06-2X/6-311+ $+\mathrm{G}(3 \mathrm{df}, 3 \mathrm{pd})$ level of theory, and the corresponding Cartesian coordinates of all molecules and clusters are shown in Table S1. The molecular electrostatic potential analyses (Figure S4) indicate that the acidity and the potential of TFA to form hydrogen bond are stronger than that of a typical (nonhalogenated) atmospheric carboxylic acid, acetic acid, and a little weaker than that of SA. To investigate the interaction properties of clusters containing TFA, topological analyses were performed to calculate the electron density $\rho$ and its Laplacian $\nabla^{2} \rho$ at the bond critical points for the studied clusters (Table S2). All these topological analysis results using the atoms in molecules theory confirm the existence of hydrogen bond interactions between TFA and SA or DMA, and the relatively high values of $\rho$ and $\nabla^{2} \rho$ indicate that most of these interactions are strong hydrogen bonds.

The stability of clusters was further studied from the perspective of thermodynamics and kinetics. Table 1 shows the Gibbs free energies for cluster formation at a reference pressure of $1 \mathrm{~atm}$ and the overall evaporation coefficients of $(\mathrm{SA})_{x} \cdot(\mathrm{DMA})_{y} \cdot(\mathrm{TFA})_{z}(1 \leq y \leq(x+z) \leq 3,1 \leq x, 1 \leq z)$ clusters. Overall evaporation coefficients for other clusters of interest are shown in Table S3. Since lower Gibbs free energy and lower evaporation rate of clusters indicate higher stability, clusters with equal numbers of acidic and basic molecules, for example, $(\mathrm{SA})_{1} \cdot(\mathrm{DMA})_{2} \cdot(\mathrm{TFA})_{1}$ and $(\mathrm{SA})_{2} \cdot(\mathrm{DMA})_{3} \cdot(\mathrm{TFA})_{1}$, are more stable than clusters with more acidic molecules than basic ones, for example, $(\mathrm{SA})_{1} \cdot(\mathrm{DMA})_{1} \cdot(\mathrm{TFA})_{1},(\mathrm{SA})_{2} \cdot(\mathrm{DMA})_{2} \cdot(\mathrm{TFA})_{1}$, and $(\mathrm{SA})_{1} \cdot(\mathrm{DMA})_{2} \cdot(\mathrm{TFA})_{2}$, which is consistent with results in previous computational studies (Elm, 2017; Olenius et al., 2013). In addition, for clusters containing the same number of acidic and basic molecules, a cluster with only one TFA molecule, for example, $(\mathrm{SA})_{2} \cdot(\mathrm{DMA})_{3} \cdot(\mathrm{TFA})_{1}$, is more stable than that involving two TFA molecules, for example, $(\mathrm{SA})_{1} \cdot(\mathrm{DMA})_{3} \cdot(\mathrm{TFA})_{2}$. Thus, taking a comprehensive look at the above two points, the most stable clusters involving TFA are $(\mathrm{SA})_{1} \cdot(\mathrm{DMA})_{2} \cdot(\mathrm{TFA})_{1}$ and $(\mathrm{SA})_{2} \cdot(\mathrm{DMA})_{3} \cdot(\mathrm{TFA})_{1}$, which might have the potential to play nonnegligible roles in a SA-DMA-TFA NPF system.

\subsection{Cluster Formation Mechanism}

In order to understand the clustering at the molecular level, ACDC (McGrath et al., 2012) was used to simulate cluster formation processes in the SA-DMA-TFA system under atmospherically relevant conditions. Figure 1a shows the cluster formation routes at $280 \mathrm{~K}$, which is chosen to match the typical conditions during the ambient observation. Generally, two separate routes, one without the participation of TFA (hereafter referred as the SA/DMA nucleation route) and the other with the participation of TFA (hereafter referred as the SA/DMA/TFA nucleation route), are evident. The two routes share a common beginning, the $(\mathrm{SA})_{1} \cdot(\mathrm{DMA})_{1}$ cluster, which is formed from the collision between one SA molecule and one DMA molecule as an acid-base pair. Subsequently, the $(\mathrm{SA})_{1} \cdot(\mathrm{DMA})_{1}$ cluster grows to larger sizes mainly by the accretion of another $(\mathrm{SA})_{1} \cdot(\mathrm{DMA})_{1}$ cluster in the SA/DMA nucleation route, as shown by the black arrows in Figure 1a. This route also involves the stepwise addition of one SA molecule followed by one DMA molecule, as shown by the gray arrows. On the other hand, in the SA/DMA/TFA nucleation route, the (SA) $)_{1} \cdot(\mathrm{DMA})_{1}$ cluster first bonds to one TFA molecule forming a $(\mathrm{SA})_{1} \cdot(\mathrm{DMA})_{1} \cdot(\mathrm{TFA})_{1}$ cluster and then to one DMA molecule resulting in a $(\mathrm{SA})_{1} \cdot(\mathrm{DMA})_{2} \cdot(\mathrm{TFA})_{1}$ cluster. The $(\mathrm{SA})_{1} \cdot(\mathrm{DMA})_{2} \cdot(\mathrm{TFA})_{1}$ cluster could grow out of the simulated system either by a direct addition of a $(\mathrm{SA})_{2} \cdot(\mathrm{DMA})_{2}$ cluster or by the accretion of one $(\mathrm{SA})_{1} \cdot(\mathrm{DMA})_{1}$ cluster, followed 

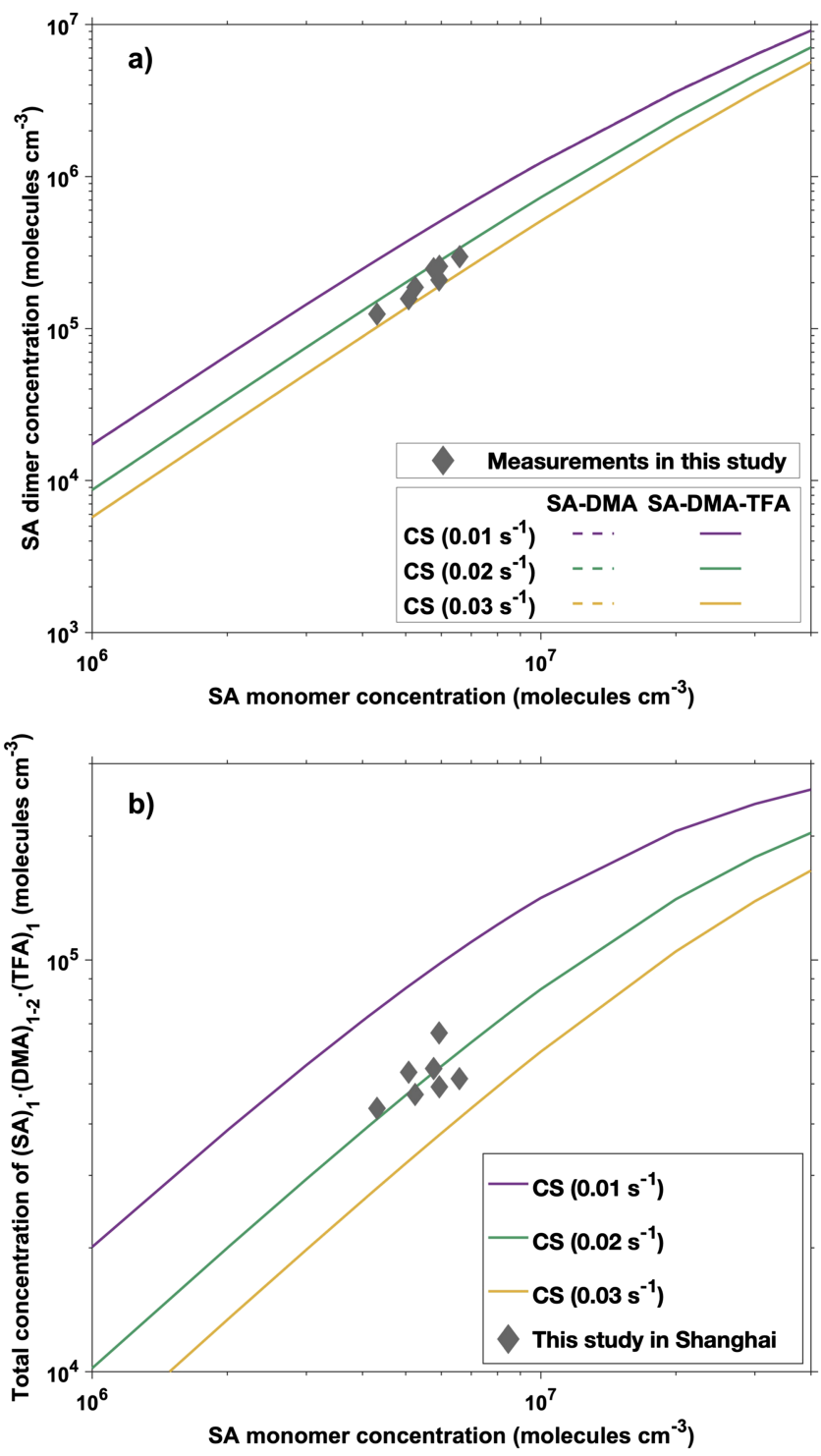

Figure 3. (a) SA dimer concentration (molecules $\mathrm{cm}^{-3}$ ) as a function of SA monomer concentration (molecules $\mathrm{cm}^{-3}$ ). The SA monomer is defined to include both free SA molecules and (SA) $)_{1}(\mathrm{DMA})_{1}$ cluster as discussed in section S1. Gray diamonds denote atmospheric measurements in urban Shanghai. The predicted SA dimer versus SA monomer plots, color coded by CS values, for the SA-DMA system and SA-DMA-TFA system from cluster kinetic simulations are shown in dashed and solid lines, respectively. (Note that the lines overlap almost perfectly). Key inputs for cluster kinetic simulations include a temperature of $280 \mathrm{~K},[\mathrm{TFA}]=5.0 \times 10^{6}$ molecule $\mathrm{cm}^{-3}$, $[\mathrm{DMA}]=1.5 \times 10^{9}$ molecules $\mathrm{cm}^{-3}$, and a sticking probability for collisions of 0.5 (details in section S1, Tables S12 and S13, and Figure S1). (b) Total concentration (molecules $\mathrm{cm}^{-3}$ ) of $(\mathrm{SA})_{1} \cdot(\mathrm{DMA})_{1-2} \cdot(\mathrm{TFA})_{1}$ as a function of SA monomer concentration (molecules $\mathrm{cm}^{-3}$ ). Gray diamonds denote atmospheric measurements in urban Shanghai. Predicted results from cluster kinetic simulations under different CS values are shown in solid lines. by further growth of the resulting $(\mathrm{SA})_{2} \cdot(\mathrm{DMA})_{3} \cdot(\mathrm{TFA})_{1}$. The involvement of $(\mathrm{SA})_{1} \cdot(\mathrm{DMA})_{2} \cdot(\mathrm{TFA})_{1}$ and $(\mathrm{SA})_{2} \cdot(\mathrm{DMA})_{3} \cdot(\mathrm{TFA})_{1}$ clusters in the SA/DMA/TFA nucleation route is mainly due to their low evaporation coefficients. Clusters with relatively high evaporation coefficients (such as $1.0 \times 10^{2} \mathrm{~s}^{-1}$ for $\left.(\mathrm{SA})_{1} \cdot(\mathrm{DMA})_{1} \cdot(\mathrm{TFA})_{2}\right)$ likely make negligible contributions in the nucleation route. Overall, the SA/DMA nucleation route accounts for $77 \%$ of the cluster formation rate, $J$, whereas the SA/DMA/ TFA nucleation route explains 19\% (the remaining $4 \%$ originates from other minor routes, which are not shown for simplicity), which corresponds to an enhancement factor of 1.3. The detailed contributions of different routes to the formation of each cluster are listed in the Tables S4 and S5. This enhancement factor can be up to 2.3 (Figure S5) at the same concentration of TFA $\left(5.0 \times 10^{6}\right.$ molecules $\left.\mathrm{cm}^{-3}\right)$ but with a lower concentration of SA $\left(1.0 \times 10^{6}\right.$ molecules $\left.\mathrm{cm}^{-3}\right)$. In these conditions, the SA/DMA/ TFA nucleation route accounts for $55 \%$ of the total $J$ (Table S4). Minor changes in the simulation parameters (CS, sticking probability, and SA and DMA concentrations) have little influence on the enhancement factor caused by TFA (Table S6). Although the enhancement on the cluster formation rate by TFA is negligible (Table S7) at a lower DMA concentration $\left(1.5 \times 10^{8}\right.$ molecules $\left.\mathrm{cm}^{-3}\right)$, the main concern of this study is to understand the potential NPF mechanisms under DMA concentrations that were actually measured (Yao et al., 2016; Zheng et al., 2015).

Figure $1 \mathrm{~b}$ shows the actual Gibbs free energies (Table S8) for cluster formation at atmospherically relevant concentrations of precursor gases. In the SA/DMA nucleation route, growth of clusters does not need to overcome thermodynamic barriers, which is consistent with the conclusions in previous studies that SA-DMA nucleation is thermodynamically favorable (Almeida et al., 2013; Olenius et al., 2013; Yao et al., 2018). In contrast, the $(\mathrm{SA})_{1} \cdot(\mathrm{DMA})_{1} \cdot(\mathrm{TFA})_{1}$ cluster is $3.98 \mathrm{kcal} \mathrm{mol}^{-1}$ higher in free energy than the $(\mathrm{SA})_{1} \cdot(\mathrm{DMA})_{1}$ cluster. In other words, the route through $(\mathrm{SA})_{1} \cdot(\mathrm{DMA})_{1} \cdot(\mathrm{TFA})_{1}$ involves a modest thermodynamic barrier. In general, the actual Gibbs free energies for formation of SA-DMA-TFA clusters are higher than the corresponding SA-DMA clusters (with the same numbers of acidic and basic molecules). However, at high enough DMA concentrations, the collision rate of DMA with $(\mathrm{SA})_{1} \cdot(\mathrm{DMA})_{1} \cdot(\mathrm{TFA})_{1}$ is still competitive with TFA evaporation, which allows the SA-DMA-TFA mechanism to contribute to the overall NPF route. We note that this prediction is dependent on the quantum chemical level of theory: For example, ACDC simulations using only the M06-2X data (without the energy RI-CC2 corrections) do not predict substantial enhancement by TFA at atmospherically relevant TFA, DMA, and SA concentrations (section S1 and Table S9).

\subsection{Evidences From Ambient Observations}

Atmospheric measurements during NPF events in urban Shanghai verify the formation of key SA-DMA-TFA clusters. Figure 2 shows the charged SA molecules and its dimer in red dots and charged TFA molecules in blue dots, as well as $\left[(\mathrm{SA})_{1} \cdot(\mathrm{DMA})_{1-2} \cdot(\mathrm{TFA})_{1}\right]^{-}$clusters in green dots. The latter originate mainly from the charging of $(\mathrm{SA})_{1} \cdot(\mathrm{DMA})_{1-2} \cdot(\mathrm{TFA})_{1}$ clusters by the primary $\mathrm{NO}_{3}{ }^{-}$ions. The high-resolution peak fitting for $\left[(\mathrm{SA})_{1} \cdot(\mathrm{DMA})_{1-2} \cdot(\mathrm{TFA})_{1}\right]^{-}$clusters is given in Figure S6. As we can see from Figure 2, our current study focuses on clusters involving TFA, which is a small part of the total set of clusters potentially relevant to NPF. In addition to TFA-containing clusters, there still 
exist other unknown categories of molecules and clusters that might also contribute to the observed NPF events.

Results from the ambient measurements are further compared with those from ACDC to elucidate the potential formation mechanisms of $(\mathrm{SA})_{1} \cdot(\mathrm{DMA})_{1-2} \cdot(\mathrm{TFA})_{1}$ clusters. Figure $3 \mathrm{a}$ shows that the predicted SA dimer concentration as a function of the SA monomer concentration is practically independent of the TFA concentration (between 0 and $5.0 \times 10^{6}$ molecules $\mathrm{cm}^{-3}$ ). Instead, the dimer-to-monomer ratio depends only on the SA concentration and the CS. The latter was not directly measured in the experiments, but as shown in Figure 3a, the best agreement is obtained for CS values around $0.02-0.03 \mathrm{~s}^{-1}$. Figure $3 \mathrm{~b}$ shows the predicted and measured (section S2 and Tables S10 and S11) total concentration of (SA) 1 (DMA) $2 \cdot(\mathrm{TFA})_{1}$, as a function of the SA monomer concentration, with predictions shown for three different CS values. A good match is obtained with a CS value of $0.02 \mathrm{~s}^{-1}$. This value was therefore adopted for all other ACDC simulations. Together with the observation of $\mathrm{H}_{2} \mathrm{SO}_{4} \cdot \mathrm{HSO}_{4}{ }^{-}$clusters in Figures 2 and 3a, quantification of $(\mathrm{SA})_{1} \cdot(\mathrm{DMA})_{1-2} \cdot(\mathrm{TFA})_{1}$ clusters in Figure $3 \mathrm{~b}$ provides strong evidence that the SA-DMA-TFA nucleation mechanism involving both the SA/DMA route (Yao et al., 2018) and the SA/DMA/TFA route is relevant to the observed NPF events on 9 January 2018 in Shanghai, though there might be other unrevealed categories of molecules contributing to the observed NPF.

\section{Conclusions}

The present study shows that TFA could promote atmospheric SA-DMA nucleation and hence atmospheric nanoparticle formation. This urges a more comprehensive evaluation of usage of Freon alternatives, whose tropospheric degradation end-products (TFA) could pose unexpected climate and health effects through their participation of NPF events. Since other atmospheric perfluorocarboxylic acids could interact with SA-DMA clusters in a similar way, their roles in atmospheric nucleation should be further evaluated by a combination of theoretical calculations, laboratory simulations, and atmospheric measurements.

Nevertheless, many atmospheric trace gases are able to interact with SA, the significance of which is a result of multifactors including the nature of the interaction, atmospheric concentrations, temperature, and even relative humidity. Hence, we can tentatively conclude that NPF in our complex atmosphere may contain contributions from both well-established nucleation precursors (e.g., SA and amines) and other atmospheric species including, but not limited to, perfluorocarboxylic acids.

\section{Acknowledgments}

This work was supported by the National Key R\&D Program of China (2017YFC0209505), and the National Natural Science Foundation of China (21976015, 21925601, and 91644213). T. K. thanks the Academy of Finland for funding. H. V. thanks the European Research Council (Grant 692891DAMOCLES) and the University of Helsinki, Faculty of Science ATMATH project for funding. We acknowledge National Supercomputing Center in Shenzhen for providing the computational resources. Data presented in this article will be deposited, once the article is published, at https://pan.baidu.com/ s/1fEiRT1PxBrZ7nOGHjeYYag to the public for data sharing.

\section{References}

Almeida, J., Schobesberger, S., Kürten, A., Ortega, I. K., Kupiainen-Määttä, O., Praplan, A. P., et al. (2013). Molecular understanding of sulphuric acid-amine particle nucleation in the atmosphere. Nature, 502(7471), 359-363. https://doi.org/10.1038/nature12663

Asfin, R. E. (2019). IR spectra of hydrogen-bonded complexes of trifluoroacetic acid with acetone and diethyl ether in the gas phase. Interaction between $\mathrm{CH}$ and $\mathrm{OH}$ stretching vibrations. Journal of Physical Chemistry A, 123(15), 3285-3292. https://doi.org/10.1021/acs. jpca.8b10215

Bianchi, F., Tröstl, J., Junninen, H., Frege, C., Henne, S., Hoyle, C. R., et al. (2016). New particle formation in the free troposphere: A question of chemistry and timing. Science, 352(6289), 1109-1112. https://doi.org/10.1126/science.aad5456

Bork, N., Elm, J., Olenius, T., \& Vehkamäki, H. (2014). Methane sulfonic acid-enhanced formation of molecular clusters of sulfuric acid and dimethyl amine. Atmospheric Chemistry and Physics, 14(22), 12,023-12,030. https://doi.org/10.5194/acp-14-12023-2014

Dawson, M. L., Varner, M. E., Perraud, V., Ezell, M. J., Gerber, R. B., \& Finlayson-Pitts, B. J. (2012). Simplified mechanism for new particle formation from methanesulfonic acid, amines, and water via experiments and ab initio calculations. Proceedings of the National Academy of Sciences of the United States of America, 109(46), 18,719-18,724. https://doi.org/10.1073/pnas.1211878109

Dunne, E. M., Gordon, H., Kürten, A., Almeida, J., Duplissy, J., Williamson, C., et al. (2016). Global atmospheric particle formation from CERN CLOUD measurements. Science, 354(6316), 1119-1124. https://doi.org/10.1126/science.aaf2649

Dunning, J., Peterson, K. A., \& Wilson, A. K. (2001). Gaussian basis sets for use in correlated molecular calculations. X. The atoms aluminum through argon revisited. Journal of Chemical Physics, 114(21), 9244-9253. https://doi.org/10.1063/1.1367373

Elm, J. (2017). Elucidating the limiting steps in sulfuric acid-base new particle formation. Journal of Physical Chemistry A, 121(43), 8288-8295. https://doi.org/10.1021/acs.jpca.7b08962

Elm, J., Bilde, M., \& Mikkelsen, K. V. (2012). Assessment of density functional theory in predicting structures and free energies of reaction of atmospheric prenucleation clusters. Journal of Chemical Theory and Computation, 8(6), 2071-2077. https://doi.org/ $10.1021 / \mathrm{ct} 300192 \mathrm{p}$

Hättig, C., \& Weigend, F. (2000). CC2 excitation energy calculations on large molecules using the resolution of the identity approximation. Journal of Chemical Physics, 113(13), 5154-5161. https://doi.org/10.1063/1.1290013

Jokinen, T., Sipilä, M., Kontkanen, J., Vakkari, V., Tisler, P., Duplissy, E. M., et al. (2018). Ion-induced sulfuric acid-ammonia nucleation drives particle formation in coastal Antarctica. Science Advances, 4(11), eaat9744. https://doi.org/10.1126/sciadv.aat9744

Kürten, Andreas, Li, C., Bianchi, F., Curtius, J., Dias, A.,Donahue, N. M., et al. (2018). New particle formation in the sulfuricaciddimethylamine-water system: Reevaluation of CLOUD chamber measurements andcomparison to an aerosol nucleation and growth model. Atmospheric Chemistryand Physics, 18(2), 845-863. https://doi.org/10.5194/acp-18-845-2018 
Kulmala, M., Kontkanen, J., Junninen, H., Lehtipalo, K., Manninen, H. E., Nieminen, T., et al. (2013). Direct observations of atmospheric aerosol nucleation. Science, 339(6122), 943-946. https://doi.org/10.1126/science.1227385

Li, H., Kupiainen-Määttä, O., Zhang, H., Zhang, X., \& Ge, M. (2017). A molecular-scale study on the role of lactic acid in new particle formation: Influence of relative humidity and temperature. Atmospheric Environment, 166, 479-487. https://doi.org/10.1016/j. atmosenv.2017.07.039

Li, H., Ning, A., Zhong, J., Zhang, H., Liu, L., Zhang, Y., et al. (2020). Influence of atmospheric conditions on sulfuric acid-dimethylamineammonia-based new particle formation. Atmospheric Environment, 245, 125554. https://doi.org/10.1016/j.chemosphere.2019.125554

Li, H., Zhang, X., Zhong, J., Liu, L., Zhang, H., Chen, F., et al. (2018). The role of hydroxymethanesulfonic acid in the initial stage of new particle formation. Atmospheric Environment, 189, 244-251. https://doi.org/10.1016/j.atmosenv.2018.07.003

Li, H., Zhong, J., Vehkamaki, H., Kurtén, T., Wang, W., Ge, M., et al. (2018). Self-catalytic reaction of $\mathrm{SO}_{3}$ and $\mathrm{NH}_{3}$ to produce sulfamic acid and its implication to atmospheric particle formation. Journal of the American Chemical Society, 140(35), 11,020-11,028. https://doi.org/ $10.1021 /$ jacs.8b04928

Lin, Y., Ji, Y., Li, Y., Secrest, J., Xu, W., Xu, F., et al. (2019). Interaction between succinic acid and sulfuric acid-base clusters. Atmospheric Chemistry and Physics, 19(12), 8003-8019. https://doi.org/10.5194/acp-19-8003-2019

Mao, J., Yu, F., Zhang, Y., An, J., Wang, L., Zheng, J., et al. (2018). High-resolution modeling of gaseous methylamines over a polluted region in China: Source-dependent emissions and implications of spatial variations. Atmospheric Chemistry and Physics, 18(11), 7933-7950. https://doi.org/10.5194/acp-18-7933-2018

McGrath, M. J., Olenius, T., Ortega, I. K., Loukonen, V., Paasonen, P., Kurtén, T., et al. (2012). Atmospheric Cluster Dynamics Code: A flexible method for solution of the birth-death equations. Atmospheric Chemistry and Physics, 12(5), 2345-2355. https://doi.org/10.5194/ acp-12-2345-2012

Nahringbauer, I., Lundgren, J.-O., \& Andersen, E. K. (1979). Trifluoroacetic acid. Acta Crystallographica Section B, 35, 508-510. https://doi. org/10.1107/S0567740879004015

Olenius, T., Kupiainen-Määttä, O., Ortega, I. K., Kurtén, T., \& Vehkamäki, H. (2013). Free energy barrier in the growth of sulfuric acidammonia and sulfuric acid-dimethylamine clusters. Journal of Chemical Physics, 139(8). https://doi.org/10.1063/1.4819024

Schobesberger, S., Junninen, H., Bianchi, F., Lönn, G., Ehn, M., Lehtipalo, K., et al. (2013). Molecular understanding of atmospheric particle formation from sulfuric acid and large oxidized organic molecules. Proceedings of the National Academy of Sciences of the United States of America, 110(43), 17223-17228. https://doi.org/10.1073/pnas.1306973110

Shampine, L. F., \& Reichelt, M. W. (1997). The MATLAB ode suite. SIAM Journal on Scientific Computing, 18(1), 1-22. https://doi.org/ $10.1137 /$ S1064827594276424

Sipilä, M., Sarnela, N., Jokinen, T., Henschel, H., Junninen, H., Kontkanen, J., et al. (2016). Molecular-scale evidence of aerosol particle formation via sequential addition of $\mathrm{HIO}_{3}$. Nature, 537(7621), 532-534. https://doi.org/10.1038/nature19314

Tromp, T. K., Ko, M. K. W., Rodriguez, J. M., \& Sze, N. D. (1995). Potential accumulation of a CFC-replacement degradation product in seasonal wetlands. Nature, 376, 327-330.

Wang, Z., Wang, Y., Li, J., Henne, S., Zhang, B., Hu, J., \& Zhang, J. (2018). Impacts of the degradation of 2,3,3,3-tetrafluoropropene into trifluoroacetic acid from its application in automobile air conditioners in China, the United States, and Europe. Environmental Science and Technology, 52(5), 2819-2826. https://doi.org/10.1021/acs.est.7b05960

Wu, J., Martin, J. W., Zhai, Z., Lu, K., Li, L., Fang, X., et al. (2014). Airborne trifluoroacetic acid and its fraction from the degradation of HFC-134a in Beijing, China. Environmental Science and Technology, 48(7), 3675-3681. https://doi.org/10.1021/es4050264

Xiao, S., Wang, M. Y., Yao, L., Kulmala, M., Zhou, B., Yang, X., et al. (2015). Strong atmospheric new particle formation in winter in urban Shanghai, China. Atmospheric Chemistry and Physics, 15(4), 1769-1781. https://doi.org/10.5194/acp-15-1769-2015

Xie, H., Elm, J., Halonen, R., Myllys, N.,Kurtén, T., Kulmala, M., \& Vehkamäki, H. (2017). Atmospheric fate ofmonoethanolamine: Enhancing new particle formation of sulfuric acid as animportant removal process. Environmental Science and Technology, 51(15), 8422-8431. https://doi.org/10.1021/acs.est.7b02294

Yao, L., Garmash, O., Bianchi, F., Zheng, J., Yan, C., Kontkanen, J., et al. (2018). Atmospheric new particle formation from sulfuric acid and amines in a Chinese megacity. Science, 361(6399), 278-281. https://doi.org/10.1126/science.aao4839

Yao, L., Wang, M. Y., Wang, X. K., Liu, Y. J., Chen, H. F., Zheng, J., et al. (2016). Detection of atmospheric gaseous amines and amides by a high-resolution time-of-flight chemical ionization mass spectrometer with protonated ethanol reagent ions. Atmospheric Chemistry and Physics, 16(22), 14,527-14,543. https://doi.org/10.5194/acp-16-14527-2016

Zhang, B., Zhai, Z., \& Zhang, J. (2018). Distribution of trifluoroacetic acid in gas and particulate phases in Beijing from 2013 to 2016. Science of the Total Environment, 634, 471-477. https://doi.org/10.1016/j.scitotenv.2018.03.384

Zhao, Y., \& Truhlar, D. G. (2008). The M06 suite of density functionals for main group thermochemistry, thermochemical kinetics, noncovalent interactions, excited states, and transition elements: Two new functionals and systematic testing of four M06-class functionals and 12 other functionals. Theoretical Chemistry Accounts, 120(1-3), 215-241. https://doi.org/10.1007/s00214-007-0310-x

Zheng, J., Ma, Y.,Chen, M., Zhang, Q., Wang, L., Khalizov, A. F., et al. (2015). Measurement of atmospheric amines and ammonia using the high resolution time-of-flight chemical ionization mass spectrometry. Atmospheric Environment, 102, 249-259. https://doi.org/10.1016/ j.atmosenv.2014.12.002 